\title{
Efectos ambientales y sociales de la minería y las curtiembres: dos escenarios estratégicos en la cuenca media del río Tunjuelo
}

\author{
En el contexto de la administración pública distrital y las \\ políticas neoliberales en Colombia
}

\section{Environmental and social impacts of mining and tanneries, two strategic stages in the middle watershed of Tunjuelo river}

\section{Nubia Barrera Silva*}

\begin{abstract}
Resumen
Este artículo aborda dos escenarios estratégicos de la cuenca media de Tunjuelo: explotación minera, materiales de construcción y arcilla en el Parque Minero Industrial PMI. Además de la producción de curtiembres en el barrio San Benito: por tradición histórica, evaden las normas ambientales con sinfín de esguinces jurídicos, niegan el derecho a la salud y a la vida digna de los habitantes ubicados en el perímetro geográfico de su influencia. En el caso de las multinacionales, la generación de riqueza es causa subyacente del deterioro de acuíferos, del hábitat y las condiciones de salud de los habitantes. Se revela la contradicción existente entre las políticas del Gobierno Nacional con las del Gobierno Distrital en la interpretación de lo público, como derechos del ciudadano. Así mismo, se visibilizan debilidades en la gestión pública a través de gestiones institucionales.
\end{abstract}

Palabras clave: Cuenca, extracción minera, curtiembres, normativa ambiental, bienes comunes, salud pública.

Antropóloga, Exp. en Administración de Empresas y Exp. en Relaciones Industriales. Universidad Externado de Colombia. Antropóloga, Universidad del Cauca. Investigadora en ciencias interdisciplinarias en estudios socioculturales y ambientales. Docencia en pregrado, posgrado y mediación virtual. Investigadora en ciencias aplicadas. Experticia en redacción de módulos en mediación virtual. Nubia_barrera@cun.edu.co Blog maliaoceano.wordpress.com. 


\section{Abstract}

This article discusses two strategic scenarios of the middle basin of Tunjuelo: mining, building materials and clay in the PMI. Besides the production of tanneries in Barrio San Benito: by historical tradition, evade environmental standards with endless legal sprains; deny the right to health and a decent life for the inhabitants located in the geographical scope of their influence. For multinationals, wealth generation is underlying cause of the deterioration of aquifers, housing and health conditions of the inhabitants. The contradiction between the policies of the National Government with the District Government in the interpretation of the public as rights of citizens is revealed. Also, weaknesses in governance become visible through institutional arrangements.

Keywords: Cuenca, mining, tanneries, environmental regulations, commons, public health.

\section{Introducción}

Se seleccionan dos escenarios estratégicos de la cuenca media de Tunjuelo en el sur de Bogotá: la extracción de arenas, conglomerados y gravas por parte de las multinacionales Holcim, Cemex y de la Fundación San Antonio de la Arquidiócesis de Bogotá, en el Parque Minero Industrial PMI, e incluye el análisis del Estado pro minero en beneficio de intereses de los países del norte en contraste con construcciones teóricas de los bienes comunes. En cuanto al sector de las curtiembres de San Benito, se presentan cifras que difieren en cronologías de antigüedad; sin embargo, existen avances muy lentos en el manejo de residuos peligrosos y/aguas residuales, generadores de riesgo en la salud tanto de los trabajadores de las empresas como de los habitantes del barrio. El rasgo distintivo es el mínimo cumplimiento de la normativa ambiental.

Se orienta este artículo por la siguiente disertación: En la parte media de la cuenca de Tunjuelo, los intereses económicos, a gran escala, del PMI y las curtiembres de San Benito, al evadir las normas ambientales con argucias jurídicas y tráfico de intereses, distorsionan las funciones de buen gobierno de la administración pública del Distrito, en detrimento ambiental de la cuenca y en la salud de los habitantes del sector. 


\section{Metodología}

Este artículo corresponde a la investigación documental de la ejecución del proyecto de investigación ${ }^{1}$ de tipo cualitativointerpretativo. Las técnicas del trabajo de campo se basaron en la observación, aplicación de encuestas y entrevistas semi-estructuradas. La motivación de la autora para escribir esta indagación documental se basó en la necesidad de completar datos e información generada por actores de multinacionales, grandes y pequeñas empresas privadas, entidades del Distrito y del Gobierno Nacional que inciden directamente en la cotidianidad de los habitantes de los territorios compartidos en común. De otro lado, esclarecer el manejo político y ambiental de la cuenca media de Tunjuelo.

Con base en la literatura existente en las instituciones del gobierno distrital e informes técnicos de universidades, se aplicó el principio de triangulación de intrasubjetidad en la evaluación de fuentes documentales y en la percepción directa de la práctica socio ambiental en la cuenca media de Tunjuelo. El propósito consistió en utilizar la literatura relevante -desde el 2007, con énfasis en los últimos cuatro años- para el análisis y la construcción de correlaciones significativas entre las actividades de extracción de recursos naturales, desviaciones sistemáticas del cauce del río Tunjuelo con fines de lucro empresarial, interpretación de normas ambientales e impacto en las condiciones de vida de habitantes de barrios afectados por el incremento de los riesgos en la salud. Se detectó que la mayoría de estudios del componente ambiental y su reglamentación normativa, abordan los mismos temas, aunque gran parte de ellos tiende a actualizarse en estadísticas. Son trabajos descriptivos, apenas enuncian complejas problemáticas de la realidad distrital. Sobresale la propensión a generar distorsiones en la gestión pública ambiental en el marco de los derechos del ciudadano que habita la cuenca.

$1 \quad$ Los ámbitos comunes: El agua, la salud pública, la seguridad social y la cultura en los habitantes de áreas de la cuenca de Tunjuelo. Bogotá D.C. 


\section{Generalidades}

La cuenca de Tunjuelo nace en el Páramo de Sumapaz, principal afluente del río Bogotá, está formada por los ríos Chisacá, Mugroso y Curubital; recorre ocho localidades e involucra 31.515 hectáreas en el área rural y 7.485 hectáreas en la parte urbana, recorre alrededor de 1.475 barrios (Ramírez, 2009). Lo que es más, la localidad de Tunjuelito asienta cerca de tres millones de habitantes de estratos uno y dos; el poblamiento carece de planeación urbanística con predominio de fami-empresa que define una actividad familiar independiente en la vivienda con respecto a micro y pequeña empresa, en contraste con el reducido número de grandes industrias con importantes capitales.

Se destacan en la parte alta de la cuenca las actividades productivas superpuestas a la unidad ecológica, "piso alto andino muy frío de la vertiente oriental y occidental de la cordillera oriental con importantes bosques alto andinos y páramos que deben ser conservados en su totalidad" (Secretaría Distrital de Ambiente, 2007, p. 27). Añade que el componente biofísico minimiza las presiones de las actividades agrícolas, especialmente de papa y otras de tipo pecuario. Tiene importancia regional por presencia de ecosistemas estratégicos situados en los macizos de Chingaza y de Sumapaz, en la regulación hídrica de ambas vertientes para el abastecimiento de agua en Bogotá, que trasvasa el recurso hídrico de sus cuencas.

\section{La minería en Tunjuelo}

El Plan de Ordenamiento Territorial POT del Distrito ha permitido, en zonas específicas, la explotación minera de materiales de construcción y de arcillas en la sabana de Bogotá de "manera transitoria aprovechando al máximo sus reservas bajo parámetros de sostenibilidad ambiental" (Colombia, Ley 99 de 1993 art. 61). A esto se añade la Sentencia C-293/o2 de la Corte Constitucional al declarar exequible el principio de precaución consagrado en el numeral 6 del artículo 1 de la Ley 99/93: "Hace clara alusión a la prevalencia del 
derecho colectivo al ambiente sano, frente a los derechos de carácter particular y concreto como el derecho al trabajo, a la libre empresa, la iniciativa privada y los denominados derechos adquiridos" (Fierro, 2011, p.13).

De añadidura, la Ley 99/93, en el artículo 61, declara: la "Sabana de Bogotá, sus páramos, aguas, valles aledaños, cerros circundantes y sistemas montañosos, como de interés ecológico nacional, cuya destinación prioritaria será la agropecuaria y forestal" (Colombia, Ley 99 de 1993, art. 61). No obstante, durante más de cincuenta años, las multinacionales Holcim -incluso dentro de la Escuela de ArtilleríaCemex Colombiana SA y la Fundación San Antonio de la Arquidiócesis de Bogotá, entidad que posee desde la Colonia un título de acceso al subsuelo para extraer arenas y gravas de las riberas del río Tunjuelo, vulneran las normativas ambientales y afectan el entorno vital de los habitantes del sector.

Los descalabros ambientales no esperan, el embalse de La Regadera, situado en la cuenca media del río Tunjuelo, en periodos de invierno "permanece normalmente lleno y produce un efecto muy pequeño en la amortiguación de las crecientes que afectan la cuenca baja del río Tunjuelo" (Rincón \& Cepeda, 2007, p. 66). Ahora bien, el territorio de la localidad de Tunjuelito, en la zona plana de la cuenca, generó tres grandes inundaciones en 1959, 1993 y 2002. La del 9 de junio de 2002 creó problemas de desbordamiento, La Regadera se rebosó en la cantera Pozo Azul, el nivel superó el borde derecho hacia el potrero dentro de la Escuela de Artillería y escurrió finalmente hacia la quebrada Chingaza y a los barrios Tunjuelito, Abraham Lincoln y San Benito. Alcanzó niveles de 2,5 metros sobre la carrera 14 del barrio Tunjuelito y parque del Hoyo, y afectó a cientos de familias del sector (Rincón \& Cepeda, 2007). Todavía más, en la memoria colectiva de los habitantes y actores externos de esta parte de la cuenca del río está la inundación de 2002, que almacenó el agua en las canteras convirtiéndose en catástrofe socio ambiental: 
(...) las aguas de las lagunas artificiales creadas por la inundación entraron en proceso de descomposición resultado del vertimiento de coliformes fecales, el depósito de basuras y el vertimiento de aguas servidas, por lo que el sector se ha convertido en foco de vectores, olores ofensivos y enfermedades (Rincón \& Cepeda, 2007, p. 67).

Como se ve, las empresas extractivas omitieron las normas de protección y conservación ambiental. Adviértase que, el artículo 9 del Decreto 1220 de 2005 el Ministerio de Medio Ambiente aprobó los Planes de Manejo Ambiental de las Empresas HOLCIM de Colombia SA, CEMEX Colombia SA y la Fundación San Antonio por tratarse de proyectos de Gran Minería. En cuanto a la salud de los habitantes del territorio compartido en común, se ignoró los efectos de las condiciones sanitarias y de habitabilidad de la población afectada por excesiva acumulación de aguas estancadas, convirtiendo las cárcavas en criaderos de insectos transmisores de enfermedades de origen hídrico. Después, surgió la intervención interinstitucional del gobierno. Es usual en el país que, después de catástrofes socio ambientales, intervengan las entidades de gobierno, ONG y consultores técnicos privados con propuestas y acciones de mejoramiento, en este caso del río Tunjuelo. Sobre el particular, Rincón \& Cepeda (2007) mencionan acuerdos para:

realizar reuniones lideradas por la Alcaldía Distrital donde estén presentes las entidades oficiales y privadas que tienen campos de trabajo relacionado con el medio ambiente, salud, control de riesgos y emergencias, infraestructuras viales, servicios públicos, y las comunidades afectadas, con el fin de establecer medidas, proyectos y controles de prevención, y no esperar a que ocurran las emergencias para tomar medidas (p. 71).

Se subraya que el propósito del trabajo en conjunto se quedó en la intención. Los habitantes subsistieron en desamparo enfrente de la devastación del capital privado, con el agravante de la destrucción de acuíferos en la parte media de la cuenca. En situaciones de emergencia social, se visibiliza la dimensión de la desarticulación interinstitucional entre el Distrito y la nación, agravada por incompetencias en la aplicación de la normativa ambiental y mecanismos de control, que de 
aplicarse hubiesen evitado tantos daños irreparables en la cuenca, la vida humana y de ecosistemas, con el agravante de la poca información disponible que sirviera de base en la reconstrucción del capital natural y humano del sector.

Dicho lo anterior, desde la década de los cincuenta se acentúa en la unidad biogeográfica de la cuenca el impacto de las explotaciones mineras de construcción en 2,34\% del territorio. Según Ramírez (2009):

estas canteras presentan varios problemas: aumento de erosión, daño en el sistema de recarga de los acuíferos, generación de fenómenos de remoción en masa, impacto visual, contaminación atmosférica, inestabilidad de taludes y generación de mayor carga de fondo en las quebradas (p.82).

Así mismo, las intensas lluvias nuevamente afectaron los taludes de las explotaciones mineras e impactaron, en el año 2009, el barrio Villa Jackie; un derrumbe en la planta de Cemex sepultó las casas de noventa familias, dejando cientos de damnificados.

Es de advertir que el monitoreo del Distrito en el área evidenció la pérdida de estabilidad del suelo por las profundas excavaciones y la consiguiente aparición de grietas, hundimientos y deslizamientos. Varias barreras construidas se encuentran a menos de 10 metros de las avenidas Boyacá y Caracas, lo cual las hace vulnerables a la tragedia. Seguidamente, por desviar y modificar el cauce del río Tunjuelo, el Distrito ordenó la suspensión de actividades mineras mediante la Resolución No 4626 del 3 de junio de 2010 como medida preventiva. De otro lado, la Resolución No 00266 del 11 de marzo de 2013 y la Resolución 00374 del 8 de abril de 2013 niegan a Holcim Colombia SA y a la Fundación San Antonio las solicitudes de concesión de aguas subterráneas e indican que no podrá hacer uso del recurso hídrico subterráneo en el área correspondiente a los títulos mineros 8151 y 048 respectivamente, ni adelantar acción alguna que conlleve una afectación del mismo (Cabrera, 2014). 
Posteriormente, Gutiérrez (Elespectador.com, 2009) entregó a la opinión pública la dimensión en cifras de la astronómica ganancia en el momento de firmar el Memorando de Entendimiento entre el Distrito y las tres cementeras, al pretender la extensión del PMI de Tunjuelo para extraer 350 millones de metros cúbicos de grava, avaluados en $\$ 1,7$ billones. De inmediato, los actores y líderes ambientalistas volvieron a recordar la tragedia social de los casi dos millones de habitantes del sector por los constantes cambios en el cauce del río como producto de la actividad minera. Añádase que, sin importar las demandas de la comunidad, el Ministerio de Defensa otorgó el aval para trasladar la Escuela de Artillería y permitir el acceso al "codiciado tesoro", con el agravante de modificar nuevamente el cauce del río Tunjuelo.

Así, se considera que los puntos del conflicto de intereses confluyen en: (a) Antes de iniciar la millonaria explotación debían retirar las demandas por daños y perjuicios entabladas contra Bogotá tras el desbordamiento del río, que en 2002 les inundó sus actuales minas en el sector. Por su parte, las tres cementeras insistieron en obtener el permiso y después desistir en las demandas estimadas en \$279.000 millones. (b) Las cementeras, en lugar de ceder el 5 por ciento de la grava de la nueva explotación (valorado en unos \$85.00o millones) para mantenimiento de la malla vial de la zona, lugar del transporte del pesado material, propusieron venderlo "barato". (c) Tampoco accedieron a compensar al Distrito por los gastos incurridos en amainar los efectos del desbordamiento del río en las minas, entre ellos la proliferación de vectores, malos olores y enfermedades en la población cercana. Argumentaron que ese es trabajo del Estado. (d) La Alcaldía les pidió que, al término de la explotación, parte del terreno fuese adecuado para vivienda de interés social. Las multinacionales afirmaron que el terreno no era apto para ese uso y que harían un gran parque, cuyo equipamiento debía pagar la ciudad (Gutiérrez, 2009). El resultado fue el posterior análisis de las exigencias para la firma del 
Efectos ambientales y sociales de la minería y las curtiembres...

memorando de entendimiento. Por su parte, el Secretario de Ambiente (citado por Elespectador.com, 2010) afirmó que:

\begin{abstract}
Eldaño ambiental causado por el desarrollo irresponsabley desordenado de la actividad minera es irreparable y tratar de resarcir el perjuicio causado al Tunjuelo tomará muchos años y grandes inversiones que deben ser asumidas por quienes explotaron los recursos naturales sin conciencia.
\end{abstract}

La Secretaría Distrital de Ambiente con respecto a los desvíos ilegales del cauce natural del río Tunjuelo en 1968, 1974 y 1997 sustentó la "medida preventiva" en virtud a que las empresas modificaron sin permiso el cauce del río Tunjuelo; usaron de manera ilegal las aguas, atentaron contra el recurso hídrico durante sus operaciones, en virtud a que excavaron por debajo del nivel freático, que es el límite en el que ocurre la recarga de acuíferos subterráneos, fundamentales para regular la calidad del suelo y la disponibilidad de aguas en épocas de escasez, sequías o emergencias por desastres naturales (De Roux, 2010).

He aquí, pues, que la Secretaría Distrital de Ambiente mediante Resolución 4626 del 3 de junio de 2010 la Secretaría Distrital de Ambiente impuso medida preventiva consistente en la suspensión de actividades de explotación minera de conformidad con el artículo 95 del Código de Minas en actividades del PMI relacionadas con extracción o captación de minerales del subsuelo, hasta tanto se cumplan las normativas ambientales que aseguren la explotación minera sin mayor perjuicio a la cuenca. ${ }^{2}$ Conviene señalar que las sanciones económicas

2 Referencia: Recurso de apelación contra el auto de 4 de agosto de 2011, proferido por el Tribunal Administrativo de Cundinamarca. Radicación número: 25000-23-26-000-2010 00768 01. “(...) especialmente, se garantice la estabilidad de los taludes y la explotación con todos los permisos ambientales que se requieren para cumplir con la actividad minera, tal como lo define el concepto técnico núm. 9036 de 31 de mayo de 2010, de conformidad con el artículo 35 de la Ley 1333 de 2009" (Consejo de Estado, 2011). De otra parte, el artículo 2 establece que se procederá a atender lo consignado en el Concepto Técnico 9036 de 31 de mayo de 2010 y ordenar a las sociedades (...) continúen al abatimiento del nivel freático hasta tanto se asegure que los taludes cumplan con las condiciones de estabilidad en estado de inundación, según concepto técnico generado sobre el particular, previa visita adelantada por la Autoridad Ambiental competente. 
y penales no dependen de la Secretaría Distrital de Ambiente sino de otras autoridades. Por su parte, Cemex Colombiana S A presentó al Consejo de Estado el "Recurso de Apelación contra el auto de 4 de agosto de 2011, proferido por el Tribunal Administrativo de Cundinamarca”. La Sala (12 de abril de 2012) ratica a Cemex la medida preventiva en defensa y protección del recurso hídrico de la cuenca.

Bajo esta perspectiva, durante décadas, la explotación minera funcionó en condiciones críticas e incitó riesgos incalculables con impacto irreversible tanto en el cauce del río, el territorio como en los habitantes de la localidad a lo largo de la cuenca de Tunjuelo en su condición de unidad biofísica, sin contar con la concesión de aguas. La travesía del río, según proyecciones, se modifica en intervalos superiores a diez años; al mismo tiempo, su cauce pierde capacidad en amortiguar las crecientes: en la parte media disminuye su fuerza, erosiona sus márgenes y desgasta el margen derecho, que delinea la curva conocida como meandro; mientras que en el margen izquierdo va depositando los materiales que arrastra el río hacia las áreas de inundación. Este evento natural incide en crecidas periódicas que pueden volverse graves e incontrolables.

El alcalde de Bogotá, Gustavo Petro en agosto de 2012 anunció la intención de no renovar los títulos mineros del PMI. Esta decisión fue acogida por la Corporación Autónoma Regional de Cundinamarca CAR, e indicó que solicitaría formalmente al Ministerio de Minas y Energía incluir esta decisión en la resolución sobre el tema que expediría el Gobierno Nacional.

Las cementeras del PMI de Tunjuelo se han beneficiado de efugios legales para impedir la suspensión de la minería de construcción. En la década del 2000 del tire y afloje jurídico por demandas y contra demandas de las empresas mineras, tutelas de la comunidad por inundaciones y daños en la salud, millonarias demandas al Distrito y cierres temporales. Sin lugar a dudas, salta a la vista una cierta debilidad de las instituciones del gobierno enfrente del poder de las 
multinacionales y de la Arquidiócesis de Bogotá, la poca valoración del capital natural y el desconocimiento de las necesidades de los pobladores. No sobra indicar que los recursos naturales del subsuelo corresponden a la nación y compete al Gobierno Nacional decidir en última instancia.

\section{PMI en Tunjuelo: Las regalías, efectos en la imagen y deterioro administrativo en el Distrito Capital}

Las regalías que recibió el Distrito entre 1996 y 2005 ascendieron a \$ 1.247.409.275 y gastó, en el mismo lapso de tiempo por concepto de atención y prevención de emergencias asociadas a la actividad minera, \$7.742.654.530 en 2013. Otra vez se infieren pérdidas irreparables de recursos naturales, sin que exista compensación alguna para inversión social en el área de la cuenca. Al contrario, las acciones interinstitucionales en perspectiva nacional y distrital se someten a distintas interpretaciones normativas por las que se escurre la responsabilidad ambiental de las cementeras, en pro de grandes beneficiarios y constante desarticulación de la unidad del territorio biofísico de la cuenca del Tunjuelo.

Distintos documentos de la Secretaria de Ambiente, afirman que los daños ambientales generados por la actividad minera en el Distrito no son compensados por los recursos que por regalías de la minería legal ingresan a la capital colombiana. Representan solo el uno por ciento del total, en la relación costo-beneficio de los ingresos de la capital, es decir, unos 140 millones de pesos. De otra parte, en Bogotá apenas figuran siete predios legales con respecto a 108 en explotación. Esta práctica pone en peligro la estabilidad del terreno de las avenidas Boyacá, Caracas e incluso predios como el Portal de Transmilenio en Usme, entre otras áreas.

Cerca del 90 por ciento produce deterioro paisajístico, erosión y detrimento del recurso hídrico por arrastre de sedimentos y afectación de la flora y fauna local. De acuerdo con el Distrito, la minería en Bogotá 
ha generado deslizamientos en zonas como Tunjuelito y Mochuelo. Y más todavía, la entonces aspirante al senado Claudia López (RCN La Radio, 2014) denunció que "entre 2005 y 2010 las grandes mineras pagaron \$ 878.00o millones en impuestos y el Gobierno les devolvió \$ 1.78 billones en deducciones de renta”; después agregó que

no tiene ninguna justificación que un país como Colombia que tiene casi la mitad de su población en la pobreza le pague a las mineras hoy el doble de lo que ellas le pagan en regalías. Eso es un subsidio neto que sale del bolsillo de los colombianos (RCN La Radio, 2014).

\section{Actores informales de la minería}

La actividad de extracción minera se concentra en el PMI de Tunjuelo. Con respecto al sector informal, Fedesarrollo (2006) le atribuye "gran cantidad de recursos disponibles, facilidad de obtención de los mismos y la ausencia de mecanismos de control por parte de las autoridades" (p. 25). En el Distrito Capital existe intensa actividad extractiva de materiales de construcción (arenas, gravas y arcillas) de pequeñas y medianas minas de familias tradicionales y hereditarias en el costado oriental de Bogotá; el del valle del río Tunjuelo alcanza un 85 \% de las explotaciones.

La Defensoría del Pueblo en Colombia estima que aproximadamente el $80 \%$ de las 144 minas no poseen título minero, y apenas el $6 \%$ hizo trámite del correspondiente título en el marco del primer proceso de legalización minera (2010). La Alcaldía de Bogotá anunció la prohibición de nuevas actividades mineras en la ciudad. Por su parte, el informe de la Personería también detalló que el fallo del Consejo de Estado del 23 de junio de 2010, concluyó que en Bogotá no pueden seguir siendo explotadas, así como otras zonas de Usaquén y la Sabana de Bogotá (Portafolio, 2012).

De acuerdo con el informe de la Personería, las canteras afectan a más de 826.0oo habitantes del entorno geográfico por el alto grado de emisiones de partículas de polvo y combustibles tóxicos. El ente 
de control concluyó que la Secretaría de Ambiente las controla en su mayoría; no obstante, otras que pese a estar en la ciudad, están bajo la jurisdicción del Ministerio de Ambiente y la CAR, y agregó que "la política ambiental en Bogotá, en relación con la minería no es efectiva, ni eficiente, ni equitativa" (Portafolio, 2012). Es evidente que existe total desconocimiento y distorsión en la aplicación de los principios del desarrollo sostenible en los términos de la Constitución Nacional y la Ley 99 de 1993 (Art. $3^{\circ}$ ), en el sentido de emplazar un cerco al salvaje crecimiento económico que agrede la calidad de vida, las condiciones de salud comunitaria y el bienestar social.

La política pública, basada en el concepto de desarrollo sostenible, atiende la ordenación de los centros urbanos alrededor del agua y ecosistemas ecológicos; uso, manejoy control de actividades productivas que reduzcan distintas vulnerabilidades asociadas al cambio climático.

El cambio climático es el problema local, regional y global más inquietante. Pone en tela de juicio la herencia a que tienen derecho las generaciones futuras, por la avaricia que impulsa el neoliberalismo exacerbado en el sector de recursos naturales y el desarrollo de necesidades materiales permanentemente insatisfechas del consumo ilimitado. En este sentido, aplicar las normas de conservación y de protección ambiental enfrente de las políticas neoliberales convierte el ejercicio de la administración pública en un permanente desgaste, y las irregularidades causadas por actores políticos o funcionarios tecnócratas reversan las decisiones de los entes de control del Distrito.

Así que es acertado que la Personería conceptúe que el detrimento administrativo de las entidades del gobierno ocurre por las suspensiones que ordena el Ministerio de Ambiente o dejen de ejecutarse por parte de las alcaldías locales y, en otros casos, los mismos infractores evaden la norma cuando quitan los sellos de suspensión de actividades de explotación. Como se observa, actualmente algunas empresas dedicadas a la explotación de canteras tienen medida de suspensión de actividades, ordenada por la Secretaría de Ambiente y, sin embargo, 
“continúan llevando a cabo su actividad, basadas en permisos que la misma autoridad ambiental les ha otorgado sin el previo levantamiento de las medidas emitidas, lo que denota una falta de articulación interna en esa entidad" (Portafolio, 2012), aseguró la Personería.

No sobra advertir que la ausencia de responsabilidad social ambiental de las empresas del PMI de Tunjuelo, así como la pequeña minería legal e ilegal, incluyendo las otras acciones productivas a lo largo de la cuenca, tienen incidencia directa sobre las políticas de la locomotora minera adaptadas al contexto específico que nos ocupa. Pardo (2013) plantea que los proyectos de gran minería mostraron un rápido crecimiento durante el gobierno de Uribe gracias a la confluencia de políticas de promoción minera y seguridad inversionista, privilegios tributarios, la reducción de las regalías de sus impuestos y la eliminación del impuesto a la remesa de utilidades, y al boom de precios de los minerales. Además, la locomotora minera del gobierno de Santos (2010-2018) profundiza el modelo de rentas extractivas de recursos naturales no renovables RNNR de Uribe.

A grandes rasgos, los resultados son los siguientes: aumento de inversión extranjera en producción y exportación de minerales, pagos por impuestos y regalías. De otra parte, Rubiano (2012) sostiene que no encaja la legislación minera con estándares nacionales e internacionales de protección al medio ambiente. Se adiciona insuficiente información pública en materia de gestión ambiental. Regresando al manejo del conflicto ambiental y social por parte de las autoridades del Gobierno Nacional, evidencia en sus posturas laxas notable distanciamiento de las políticas ambientales del Gobierno Distrital. Desde esta perspectiva, puede afirmarse que:

(...) este balance es parcial no incluye los enormes impactos ambientales de las extracciones, especialmente a cielo abierto, los costos sociales en las poblaciones ubicadas en el área de influencia, la reprimarización de la economía, la conflictividad que genera su operación en zonas de precaria presencia estatal (...) (Pardo, 2013, p. 174). 
En conclusión, la política nacional beneficia el modelo extractivista de las multinacionales, reduce el ordenamiento jurídico ambiental a referentes de forma en detrimento del agua, los ecosistemas acuíferos en la ronda del río, entre otros, con daños en la salud de los habitantes del entorno, que bien podrían evitar acudir a los servicios de salud distritales en situaciones de emergencia por emergencias ambientales del sector medio. En este panorama, se entretejen intereses económicos y políticos de actores locales con articulaciones en la política nacional en contra de necesidades e intereses colectivos.

\section{VII.El papel del Norte y el Sur globales en los bienes co- munes}

La política extractiva se enmarca en el capitalismo financiero y de expoliación de RNNR en países emergentes. El nuevo orden mundial profundiza la brecha entre el Norte Global, constituido por países altamente industrializados, y el Sur Global, caracterizado por la desigualdad, la informalidad laboral, precarios modelos educativos con incidencia alarmante en los satisfactores de la necesidad de subsistencia de la gran mayoría de la población, especialmente en Colombia. Se profundizan distintas formas de violencia, con una característica común: la distribución inequitativa de ingresos entre las clases sociales, sumiendo a más de la mitad de la población en la pobreza estructural, la vulnerabilidad y la economía informal. Fierro (2012) afirma que la política minera colombiana:

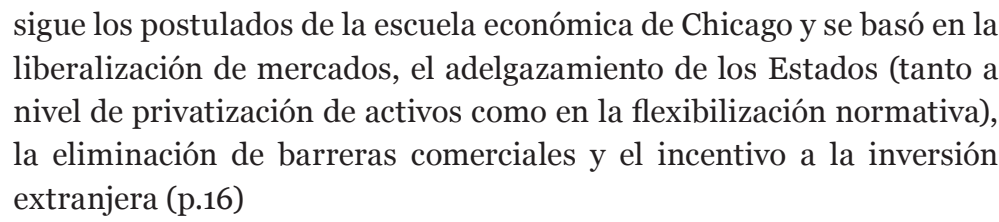

Esta política está claramente definida en la cuantía de regalías que entregan las cementeras al Distrito. Es necesario recalcar que, el uno por ciento del total de regalías que recibe el Distrito, se ajusta a la adecuación de la política de Estado -en su máxima expresión-, a 
las exigencias de las multinacionales en caída libre sobre la riqueza natural y cultural de los bienes comunes en los países del Sur Global. Fierro (2012) sostiene que la política de la locomotora minera exigió profundas

modificaciones en los Códigos mineros de la mayor parte de Latinoamérica en la década de 1990, y en Colombia la derogatoria del Decreto 2655 de 1988, reemplazado por la Ley 685 de 2001 -actual Código de Minas-, mediante la cual se aplicaron medidas regresivas como que el subsuelo pasó de ser de la Nación al Estado y se restringió la acción del Estado a un simple promotor y fiscalizador de la actividad minera (p. 16)

Es lugar conocido, en perspectiva nacional, equiparar el crecimiento del PIB por la venta de RNNR, como si se tratase de actividades provenientes de empresas productivas de bienes o servicios, ignorando tanto el valor de las personas como de sus satisfactores en la conservación de la vida. Sobre el particular, Bocking destacado pensador ambientalista canadiense (citado por Auden, 2008), precisa:

Que los Ámbitos Comunes, son esas cosas a las que tenemos derecho por el sólo hecho de ser miembros de la familia humana: "El aire que respiramos, el agua dulce que tomamos, los mares, los bosques, las montañas, la herencia genética a través de la cual se trasmite toda la vida, la diversidad de la vida misma”. (p. 247)

En este orden de ideas, el concepto de bien común articulado a la globalización económica, pone en el lugar del territorio de lo público a las corporaciones transnacionales y locales, en el sentido de negar la jerarquía de comunidad originaria en sus territorios de primigenios por el simple hecho de nacer en ellos. Auden (2008) dice que

Bien Común es sinónimo de comunidad, cooperación y respeto por los derechos y preferencias de los otros (...) los espacios públicos, las tierras comunitarias, los bosques, la reserva genética y las medicinas locales, son bienes o ámbitos comunes de comunidades particulares. (p. 247)

Bollier (citado por Auden, 2008) plantea que corresponde a los gobiernos proteger los ámbitos comunes en nombre de la ciudadanía 
y poner límites equitativos a la razón de ser de las corporaciones, encaminadas al lucro indiscriminado en detrimento del medio ambiente. Al llegar aquí, es inquietante verificar que "El mercado y sus valores establecen su dominio sobre todo, y al hacerlo erosionan el vigor de la comunidad, socavan la investigación científica abierta, debilitan la cultura democrática, y agotan la vitalidad de la economía a largo plazo" (Auden, 2008. p. 250). Esto significa que los gobiernos de países emergentes deben adecuar la política pública a la protección de los ámbitos comunes como únicos mecanismos de protección de sostenibilidad ambiental, garante de conservación de todas las formas de vida, tanto de la naturaleza como humana.

\section{VIII.Tendencia en crisis: defensa de lo público en el mar- co neoliberal de las políticas del Gobierno Nacional}

Desde el 2012, la Administración del Alcalde Mayor Gustavo Petro $^{3}$ evidenció distanciamientos entre la política neoliberal del Gobierno Nacional y la insistente defensa de lo público en el Distrito: dos posturas antagónicas mediadas por intereses de políticos profesionales, empresarios extranjeros y nacionales en permanente pugna en tribunales administrativos. Veamos ahora cómo las decisiones administrativas del Distrito amparan la sostenibilidad de los recursos naturales, en el sentido de replantear la explotación del subsuelo con respecto al monto de regalías, la inversión en infraestructura con criterios de redistribución equitativa entre el capital, uso del subsuelo y el bienestar que merecen las comunidades circunvecinas al PMI de Tunjuelo. En resumen, el choque entre el capital transnacional y el Gobierno Distrital con respecto a la política nacional deja advertir:

3 Destituido el 19 de marzo de 2014 por el Procurador General de la Nación, más el agravante de quince años de pérdida de derechos políticos. Luego, el 22 de abril de 2014, la Sala Civil del Tribunal Superior de Bogotá ordenó al presidente de la República, Juan Manuel Santos, el reintegro del destituido alcalde Gustavo Petro a su cargo (Semana, 2014). Esta decisión acoge la solicitud de medidas cautelares de la Comisión Interamericana de Derechos Humanos. (CIDH, 2014 citado en Semana, 2014). 
un Gobierno Nacional pro minero y leyes para el sector que a veces parecen capaces de sobrepasar hasta la Constitución, ¿qué puede hacer el Distrito para evitar la depredación de la minería en el casco urbano? Las alternativas se cierran, pero hay herramientas vigentes cuya aplicación sólo depende de la voluntad política de nuestras administraciones (De Roux, 2009).

En suma, el memorando de entendimiento del Distrito con las tres cementeras, consistió en autorizar la ampliación de las actividades mineras a cien hectáreas en el interior de la Escuela de Artillería del Ejército. Más aún, la aplicación de las normas ambientales logró frenar el inicio de la expansión de la explotación minera. Otro evento de discrepancia en toma de decisiones entre el Gobierno Nacional y el Gobierno Distrital, se centró en la Ley 99 de 1993 (Artículo 61), que define la sabana de Bogotá una unidad ecológica y socio ambiental de alcance nacional, por lo tanto, le concernía al Ministerio de Ambiente la potestad de decidir las áreas de explotación mineras y entrega de licencias ambientales.

De otra parte, del historial de decisiones políticas de este sector de la cuenca media de Tunjuelo, merece especial recordación la postura neoliberal del gobierno del alcalde Mockus, quien terció en beneficio de las cementeras, basándose en el mercado de construcción de viviendas en Bogotá. Finalmente, se derrumbaron las iniciativas de protección ambiental, de salud e integridad de las personas y de sus bienes en áreas aledañas a la extracción de gravillas y arenas.

En este orden de ideas, el Código de Minas establece en los artículos 95, 197 y 205 que toda explotación minera requiere licencia ambiental. Conviene señalar que la residencia de la Escuela de Artillería en la zona, por razones de seguridad nacional, impidió la expansión del PMI de Tunjuelo, circunstancia que detuvo por un tiempo la explotación minera. Sin embargo, todo cambió cuando el memorando de entendimiento también fue acordado entre aquella y el Ministerio de Defensa, y este último aceptase el traslado de la Escuela a la zona de Usme. 


\section{Las curtiembres de San Benito}

El sector de las curtiembres de San Benito de la localidad de Tunjuelito es ampliamente conocido por generación de lodos con cromo, residuos muy peligrosos y la materia prima que producen en la fabricación de productos de calzado y marroquinería, que afectan las formas de vida en la cuenca de Tunjuelo (Secretaría Distrital de Ambiente, 2007).

Los estudios del sector presentan datos disímiles por apertura, cierre o cambios de razón social de las pequeñas y medianas empresas, por la permanente presión de las autoridades ambientales del Distrito. De otra parte, la identificación del impacto de contaminantes y daños en la salud sí presenta coincidencias. El Grupo de Producción Más Limpia de la SDA de la Secretaría Distrital de Ambiente (2007):

localizó 265 curtiembres que ocuparon 283 predios, registrándose además 3 curtiembres en Usme, 2 en Ciudad Bolívar y una en Fontibón (esta última por fuera de la cuenca). Por su parte, la base de datos de la CCB registra un total de 146 curtiembres en la cuenca, contrastando con las 198. Además de esta excesiva concentración, existen 29 empresas que aprovechan los subproductos generados en la actividad curtidora (sebo, carnaza) 31 dedicadas a otras actividades. (p.221)

En adición a lo anterior, Salazar (2013) menciona en San Benito cerca de 350 curtiembres, de las cuales 75 están inscritas al proyecto del Parque Ecoeficiente de San Benito. La escasa adhesión a las prácticas ambientales se motivó en la ausencia de solicitudes de permisos a las entidades reguladoras que condujesen al manejo adecuado de aguas residuales, señaladas en el Decreto 1594 de 1984, la Ley 99 de 1993 y el Decreto 2811 de 1974, normas regionales y distritales que indican los requisitos básicos con los que debe contar cualquier tipo de industria que produzca residuos peligrosos y/o aguas residuales. Conviene señalar que las empresas y las unidades residenciales vierten las aguas residuales al sistema de alcantarillado público operado por la Empresa de Acueducto y Alcantarillado de Bogotá (EAB-ESP); éste sistema las transporta a una estación elevadora ubicada en el costado occidental 
sobre la avenida Boyacá que luego entrega al interceptor Tunjuelo medio para su transporte y vertido en el río Tunjuelo a la altura de la calle 48B sur con carrera 77J, sin ningún tipo de tratamiento por parte de la empresa EAB-ESP (Secretaría de Ambiente, 2014).

Cabe enfatizar que, entre las problemáticas que más afectan la calidad del agua, están los vertimientos de las redes de EAB-ESP en el río Tunjuelo, establecidas en el Plan de Saneamiento y Manejo de Vertimientos (PSMV). La Resolución 3257 de 2007 establece las obligaciones de la EAB-ESP en actividades de planificación y ejecución de obras de saneamiento en el río Tunjuelo y su expansión a subcuencas. De otra parte, ESE (2009-2010 citado por Salazar 2013), agrega que la falta del manejo especial de aguas residuales, la distribución de este tipo de productos con bajos niveles de seguridad industrial y un debido almacenamiento de materia primas, desperdicios, arrojo de desechos al alcantarillado de la zona, entre otras características, hacen que este barrio se vea afectado por enfermedades respiratorias y gastrointestinales.

Entre los rasgos más distintivos figuran:

(1) En las pequeñas y medianas empresas, en predios menores de 500 $\mathrm{m}^{2}$, existe la tendencia de contratar a trabajadores con altos niveles de informalidad, sin derechos laborales ni acceso a servicios sociales. (2) Prevalece la competencia desleal y bajos niveles de agremiación por excesivo individualismo; mientras que unos se ajustan a la legalidad, otros venden a bajos precios sin cumplir ninguna norma. Prueba de ello, la "Cooperativa de Curtidores de San Benito-Coopicur, agrupa sólo a 46 empresarios, es decir, menos del 20\% de las 265 identificadas". (Secretaría Distrital de Ambiente, 2007, p. 225)

En referencia a datos regionales, la CEPAL (2006) infiere que es posible constatar que el empleo generado por estos sectores tanto en Argentina y Chile como en México y Colombia, se encuentra en el rango de $75 \%$ a 90\% del total del empleo generado por el país, lo que sin duda constituye una cifra bastante alta. 
De otro lado, la CEPAL (2006) menciona que la evasión de las normas ambientales por parte del sector productivo tiene intereses económicos y avista obstáculos en logros de iniciativa empresarial, concienciación de la población, complicaciones en la salud pública ligados a la degradación ambiental por "emisiones al aire, falta de tratamiento de aguas, carencias de equipos para tratamiento y eliminación de residuos peligrosos, residuos sólidos, etc., los cuales, en un marco de desarrollo industrial sostenible, se vuelven cada vez más visibles” (p. 42).

De acuerdo a lo anterior, cobra fuerza la logística reversiva como instrumento y respuesta eficiente para el cumplimiento normativo con respecto al manejo del agua y el medio ambiente, así como la restauración que hace parte de la responsabilidad social empresarial de las industrias curtidoras. A través de su adecuada aplicación, los propietarios de estas industrias podrían implementar planes de manejo y reúso de este tipo de aguas, valorando así con mayor proporción el insumo principal (Salazar, 2013).

En respuesta, la Alcaldía Local de Tunjuelito, los industriales del cuero, la Secretaría de Ambiente y la Empresa de Acueducto y Alcantarillado de Bogotá, realizaron, en 2013, tres mesas de trabajo con participación de cerca de 150 representantes de la industria del cuero del barrio San Benito. Acometieron la temática sobre recuperación, apropiación y sensibilización de la ronda hidráulica del río Tunjuelo con acciones ecológicas que motivasen el interés por el cuidado, protección y preservación del agua y crear conciencia sobre la importancia de la cuenca, además de fortalecer el arraigo de las comunidades y personas que utilizan el sendero ecológico como espacio natural y público.

En San Benito, el proyecto que genera receptividad por parte de los empresarios es la construcción de una planta de tratamiento de aguas residuales que detenga el vertimiento de contaminantes al río Tunjuelo. Ahora bien, los resultados del análisis químico de Soto, Gutiérrez, Rey, González de la CAR (2013), en la parte media de los ríos Bogotá y Tunjuelo, detectaron altas concentraciones de cromo, plomo 
y mercurio superior a lo indicado por la norma, especialmente en el tramo 4 generado por las curtiembres ${ }^{4}$.

Finalmente, la Alcaldía Local de Tunjuelito presentó el Informe de rendición de cuentas, Vigencia de 2013, en el contexto de las funciones misionales que promuevan "un sistema centralizado de tratamiento de aguas y residuos en San Benito (minimizar vertimientos, residuos y emisiones contaminantes, de la industria del cuero en San Benito" (Secretaría Distrital de Planeación, 2013, p.13). Así mismo, incrementar la productividad, competitividad y eficiencia, a través de tecnologías limpias con estrategias de gestión interinstitucional.

\section{Conclusiones}

Se caracteriza la explotación minera del PMI y de la Arquidiócesis de Bogotá por generar hundimientos, deslizamientos, desviaciones y modificaciones del cauce del río Tunjuelo, uso ilegal y atentado en contra del recurso hídrico por debajo del nivel freático, ocasionado por profundas excavaciones que evidencian pérdida de estabilidad del suelo y destrucción de acuíferos. Afectaciones en flora y fauna local a pesar del mandato de la Ley 99/93, artículo 61, que declara la "Sabana de Bogotá, sus páramos, aguas, valles aledaños, cerros circundantes y sistemas montañosos, como de interés ecológico nacional, cuya destinación prioritaria será la agropecuaria y forestal” (Colombia, Ley 99 de 1993, art. 61).

4 "Los resultados de análisis químico en la zona media de los ríos Bogotá y Tunjuelo, detectaron la presencia de cromo hexavalente (mayor a $0.005 \mathrm{mg}$ de $\mathrm{Cr} / \mathrm{L}$ ); plomo (mayor a $0.049 \mathrm{mg}$ de $\mathrm{Pl} / \mathrm{L}$ ) y mercurio (mayor a $0.001 \mathrm{mg}$ de $\mathrm{Hg} / \mathrm{L}$.) superior a lo establecido por la norma (2010). La contaminación se incrementa con respecto al análisis químico del cromo (2007), el cual presentó mayor concentración promedio (0,2 mg/l) -con respecto a las otras es superficial y a los otros metales estudiados por la presencia de curtiembres, localizados en el tramo 4 donde descarga el interceptor que recoge las aguas residuales de San Benito. Los metales que registraron concentraciones mayores fueron el zinc y manganeso $(0,17 \mathrm{mg} / \mathrm{l})$, siendo el primero utilizado en la industria de recubrimientos metálicos y el segundo asociado a los residuos de la industria extractiva y de triturados para agregados. Además, se observa que la concentración promedio de manganeso fue mayor en el río Tunjuelo y que los otros metales estudiados mostraron valores menores de $0,2 \mathrm{mg} / \mathrm{l}$." (CAR, 2013, p. 23). 
Este documento desvela que el conflicto de la minería tiene un profundo sesgo de institucionalidad extractiva en detrimento de la salud pública, sin compensación alguna. Se muestra el deplorable contraste entre las astronómicas ganancias provenientes de RNNR, la devastación ecológico-ambiental, el deterioro de la salud humana con respecto a las insuficientes regalías que recibe el Distrito. Desde las organizaciones sociales, los habitantes afectados y las políticas socio ambientales de la Bogotá Humana, resulta inadmisible que los colombianos subsidien el doble del pago que reciben en regalías.

Desde esta perspectiva, la responsabilidad social empresarial RSE es ajena al desarrollo sostenible en cuanto a inversión en procesos de conservación por extracción de recursos naturales y ejecución de programas de salud pública. Conviene señalar que en la producción de curtiembres de San Benito, el proceso de adhesión a prácticas de RSE es incipiente en uso y manejo de aguas residuales, bajos niveles de seguridad industrial y tratamientos de materias primas.

Adviértase, pues, que la Alcaldía Local moldeó la estructura del plan de desarrollo local del territorio alrededor del agua, en consonancia con las estrategias globales, previendo compensar el deterioro ambiental, sea por la intervención humana o el cambio climático, en el sentido de preparar las comunidades a impredecibles cambios económicos, sociales y culturales, que ya amenazan con alertas tempranas. Por ejemplo, escasez de agua, sequías prolongadas, muertes de animales y secamiento de humedales en Colombia.

Es evidente que las políticas consignadas en el Plan de Desarrollo Decenal de Salud Pública 2014-2021, que declara un derecho fundamental el acceso a la salud, si bien las instituciones del sector atienden a la población afectada, solo pueden limitarse a medicar síntomas, teniendo en cuenta que comparten el mismo territorio con las cementeras. Estas últimas están dedicadas a generar riqueza para sus afiliados; en cambio, entregan la destrucción del hábitat de la cuenca: pobreza, vulnerabilidad socioeconómica y riesgos ambientales. 
Es un hecho que los habitantes de barrios aledaños no podrán tener condiciones dignas de bienestar ni desarrollo personal, familiar y comunitario.

En este orden de ideas, la decisión del Gobierno Distrital (Resolución 6921, 2010) de dejar extinguir los títulos mineros actuales con apoyo político de la CAR y del Gobierno Nacional, sería un aporte sustancial a la política pública vinculada a la conservación ecológica y sostenibilidad socio ambiental en términos de legalidad institucional. Este enfoque fortalece los ámbitos comunes y empodera a las comunidades en decisiones que afectan el legado intergeneracional de producir riqueza, conservar todas las formas de vida, fortalecer símbolos y representaciones culturales por corresponder a bienes comunes e intangibles de bienestar social y humano como lo plantea la tesis de este artículo. 


\section{Referencias bibliográficas}

Auden, W.H. M. (2008). Capítulo VI. Movimiento Internacional por el derecho humano al agua. El agua nuestro bien común hacia una nueva narrativa del agua. En Dos millones de firmas por el agua. El agua un derecho fundamental. (247-312). Bogotá: Corporación Ecofondo. Le Conseil de Canadiens. México. Centro América y el Caribe.

Bogotá. Secretaría Distrital de Ambiente. (2007). Diagnóstico POMCA Tunjuelito. Recuperado de http://oab.ambientebogota.gov.co/resultado_busquedas.php?AA_SL_ Session $=8 \mathrm{cf} 97 \& \mathrm{x}=4001$

Bogotá. Secretaría Distrital de Ambiente. (2010). Por desviar y modificar el río Tunjuelo, Cemex, Holcim y la Fundación San Antonio deberán cesar sus actividades. Recuperado de http://oab.ambientebogota.gov.co/index.shtml?apc $=m 1-1---\& x=2874 \& s=m$

Cabrera, E. Secretaría Distrital de Ambiente. Subdirección de Recurso Hídrico y del suelo (10 de abril de 2014).

CEPAL (2006). Las pymes en el mercado de bienes y servicios ambientales: identificación de oportunidades, políticas e instrumentos Estudios de caso de: Argentina, Chile, Colombia y México: Santiago de Chile. Recuperado de: http://www.eclac.cl/publicaciones/xml/6/26826/LCW42.pdf

CIDH "no acepta" decisión de Colombia de negar medidas a favor de Petro. (4 de abril, 2014). Recuperado En http://radiomacondo.fm/2014/04/04/cidh-no-acepta-decision-decolombia-de-negar-medidas-a-favor-de-petro/

Colombia. Consejo de Estado. (2012). Sala de lo Contencioso Administrativo Sección Tercera. 3 de diciembre de 2012. Recuperado en file://C:/Users/User/Music/Documents/ Downloads/aclara_sentencia.pdf

Colombia. Consejo de Estado (2014). Auto 2003-00821 de febrero 12 de 2014. Consejera Ponente: Olga Mélida Valle.

Colombia. Congreso de la República (1993). Ley 99 de 1993 por la cual se crea el Ministerio del Medio Ambiente, se reordena el Sector Público encargado de la gestión y conservación del medio ambiente y los recursos naturales renovables, se organiza el Sistema Nacional Ambiental, SINA, y se dictan otras disposiciones. Recuperado de www.alcaldiabogota.gov.co/sisjur/normas/Norma1.jsp?i=297

Corporación Autónoma Regional de Cundinamarca. CAR (2013). Adecuación Hidráulica y Recuperación ambiental Río Bogotá. Recuperado de: https://www.google.es/url?sa=t $\& r c t=j \& q=\&$ esrc $=s \&$ source $=$ web $\& c d=2 \& c a d=r j a \& u a c t=8 \& v e d=0 C C g Q F j A B a h U K E w j$ Hm6evhMTHAhVJOxoKHfaUARw\&url=https\%3A\%2F\%2Fwww.car.gov.co\%2Findex. php\%3Fidcategoria\%3D10162\%26download\%3DY\&ei=nETcVcfdEcn2aPaphuAB\&usg =AFQjCNEO33_4VmJiJuQgfthcPrCvFJLUVg\&sig2=egfx7KD9BuJiayZjMaB9sg

Defensoría del Pueblo. (2010). La minería de hecho en Colombia. Bogotá: Imprenta Nacional de Colombia.

De Roux, C. (2010, 29, junio). Ordenan suspender actividad minera en la cuenca del Tunjuelo. Recuperado de: www.carlosvicentederoux.org/index.shtml?apc=d-xx-1$\& \mathrm{~m}=6587$

De Roux, C. (2009, 24, septiembre). Caen en dominó las barreras a la explotación de la minería de Tunjuelo. Recuperado de www.carlosvicentederoux.org/index.shtml?apc=d$\mathrm{xx}-1-\& \mathrm{~m}=\mathrm{d}-\& \mathrm{x}=6641$.

(2010, 8 de junio). Cémex y Holcim deberán responder por contaminación del río Tunjuelo. Elespectador.com. Recuperado de www.elespectador.com/noticias/bogotá/cemex-yholcim-deberan-responder-contaminacion-del-rio-articulo-207341 
Fedesarrollo (2006). El sector de materiales de construcción en Bogotá-Cundinamarca. Recuperado de: http://www.repository.fedesarrollo.org.co/handle/11445/1916

Fierro, J. (2011). Minería en Bogotá: Las problemáticas están a la vuelta de la esquina. Recuperado de: http://www.slideshare.net/pepitapereque/minera-en-bogot-las-problemticas-estn-a-la-vuelta-de-la-esquina-9034857

(2012) Políticas mineras en Colombia. Bogotá: Instituto Latinoamericano para una sociedad y un derecho alternativos, Comité Catholique contre la faim et pour le développement - CCFD Terre Solidaire.

Gutiérrez, E. (2009, noviembre, 9). El Tunjuelo es una mina. Recuperado de www.elespectador.com/impreso/temadeldia/articuloimpreso171298-el-tunjuelo-una-mina

Pardo, A. (2013). La conflictividad por el territorio, el control de los RNNR y la renta minera. El choque de las locomotoras mineras en Colombia. En: Garay Salamanca, L.J. (Ed.), Minería en Colombia (143-183). Bogotá: Imprenta Nacional de Colombia.

Portafolio El 92,6\% de la minería en Bogotá es ilegal. (4 de noviembre de 2012) Recuperado en http://www.logandrillinggroup.com/logandrillingcolombia/index.php/noticias/198el-926-de-la-mineria-en-bogota-es

Ramírez, A. (2009). Análisis de los conflictos ambientales en interfases urbano-rurales Generalidades desde dos territorios de Bogotá Corporación Construyendo Hábitat. Revista nodo, 6(3), 71-96.

RCN La Radio (2014). Gobierno devuelve el doble de los impuestos que pagan las multinacionales, en exenciones. Recuperado de http://www.rcnradio.com/noticias/gobiernodevuelve-el-doble-de-los-impuestos-que-pagan-las-multinacionales-en-exenciones

Rendición de cuentas. Localidad de Tunjuelito. Vigencia de 2013. Secretaría Distrital de Planeación Dirección de Planes de Desarrollo y Fortalecimiento Local. Recuperado de http://www.veeduriadistrital.gov.co/veeduria/media/file/6_\%20TUNJUELITO\%20 RC\%202013.pdf

Rincón, M. \& Cepeda, L. (2007). Control de inundaciones del río Tunjuelito. Revista de Topografía Azimut, 1, 65-72. Recuperado de http://revistas.udistrital.edu.co/ojs/index.php/azimut/article/view/4041/o

Rubiano, S. (2012). La regulación ambiental y social de la minería en Colombia: comentarios al proyecto de ley de reforma al código de minas. Recuperado de: http://library. fes.de/pdf-files/bueros/kolumbien/o9382.pdf

Salazar, M. (2013). Implementación de logística reversiva como modelo administrativo moderno en el Sector industrial de curtiembres de San Benito en Bogotá (Tesis de grado). Universidad EAN, Bogotá, Colombia.

. (2014, 9 de diciembre). La decisión de la Procuraduría que tumbó al alcalde Petro. Semana. Recuperado de: http://www.semana.com/nacion/articulo/comunicado-dela-procuraduria-que-destituyo-petro/367698-3

. (2014, 22 de abril). Tribunal ordenó reintegro de Petro. Semana. Recuperado de http://www.semana.com/nacion/articulo/tribunal-superior-de-bogota-ordena-reintegro-de-petro-al-cargo/384489-3

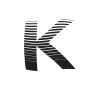

